DOI: http://dx.doi.org/10.11606/issn.1984-4867.v27i2p364-387

\title{
Festas Tradicionais no Entorno da Estrada Boiadeira no Paraná: um potencial para o turismo rural
}

\author{
Traditional Feasts Surrounding Boiadeira Road in Paraná: a potential for rural tourism \\ Fiestas Tradicionales Alrededor de la Carretera Boiadeira en Paraná: un potencial para el
turismo rural
}

Josemara Marques dos Rêis ${ }^{1}$

Juliana Teixeira ${ }^{2}$

\section{Resumo}

Devido ao crescimento da urbanização do campo, entre outros aspectos, as grandes propriedades se expandiram sobre os pequenos sitiantes que foram vendendo os seus bens e se deslocando para a cidade. Em meio a esse cenário, muitos agricultores de base familiar ainda residem no campo mesmo com diversas dificuldades. Essa é a realidade das comunidades do entorno da Estrada Boiadeira no interior do Estado do Paraná, em que os agricultores familiares ainda mantém vivas as tradições de seus antepassados como as festas religiosas, festas juninas, festas gastronômicas e demais representações sobre seu modo de vida. $\mathrm{O}$ referente trabalho teve como objetivo geral investigar a viabilidade de implantação do roteiro turístico no entorno da BR-487, conhecida como Estrada Boiadeira. A presente pesquisa tem caráter descritivo e exploratório com características de investigação qualitativa. Em uma primeira etapa foi realizada revisão da literatura em livros e artigos de periódicos especializados. Na segunda etapa foi realizada a pesquisa de campo com o intuito de levantar dados sobre as comunidades utilizando as técnicas de observação sistemática, entrevistas semiestruturadas e questionários. Foi observado como resultado que as comunidades e suas festas tradicionais possuem recursos que viabilizam a implementação de roteiro turístico no entorno da Estrada Boiadeira. Porém para que o mesmo seja estruturado com sucesso ainda faltam readequações necessárias em cada comunidade. Acredita-se que o desenvolvimento do roteiro ajudará a manter vivas as tradições culturais de cada localidade.

Palavras-chaves: Roteiro Turístico; Estrada Boiadeira; Turismo Rural.

\section{Abstract}

Due to the increasing urbanization of the countryside, among other things, large properties expanded on small farmers who were selling their goods and moving to the city. Amidst this scenario, many family-based farmers still reside in the countryside with difficulties. That is

${ }^{1}$ Bacharel em Turismo e Meio Ambiente pela Universidade Estadual do Paraná, Campus de Campo Mourão (UNESPAR). Campo Mourão, Paraná, Brasil. E-mail: josemara_marques@ hotmail.com.

${ }^{2}$ Mestra em Geografia pela Universidade Estadual de Maringá (UEM). Graduada em Turismo e Meio Ambiente pela Faculdade Estadual de Ciências e Letras de Campo Mourão (FECILCAM). Professora Assistente do curso de Graduação em Turismo e Meio Ambiente pela Universidade Estadual do Paraná, Campus Campo Mourão (UNESPAR). Campo Mourão, Paraná, Brasil. E-mail: julianatma@gmail.com. 
the reality of the communities around the Boiadeira Road in the state of Parana, where farmers still alive the traditions of their ancestors as religious festivals, county fairs, gastronomic feasts and other representations of their way of life. The related work aimed to investigate the feasibility of implementing the tourist track along the BR-487, known as Road Boiadeira. For the research, the methodology adopted was to descriptive and exploratory research with qualitative research characteristics. In the first stage was carried out bibliographic review in books and specialized journal articles. In the second stage of field research was conducted in order to collect data on communities using systematic observation techniques, semi-structured interviews and questionnaires. It has been observed as a result that communities and their traditional festivals have features that enable the implementation of tourist track surrounding the Boiadeira Road. However, for it to be successful structured readjustments there are still necessary in each community. It is believed that the development of the roadmap will help keep alive the cultural traditions of each locality.

Keywords: Tourist Guide; Boiadeira road; Rural Tourism.

\section{Resumen}

Debido a la creciente urbanización del campo, entre otros aspectos, las grandes propiedades se han ampliado en los pequeños agricultores que vendían sus bienes y se trasladaron a la ciudad. En medio de este escenario, muchos agricultores basados en la familia todavía viven en el campo mismo con varias dificultades. Esta es la realidad de las comunidades que rodea la Carretera Boiadeira dentro del estado de Paraná, donde los agricultores familiares siguen manteniendo vivas las tradiciones de sus antepasados como las fiestas religiosas, ferias, festivales gastronómicos y otras representaciones de su forma de vida. El trabajo relacionado con el objetivo de investigar la viabilidad de la aplicación de la ruta turística a lo largo de la BR-487, conocida como Carretera Boiadeira. Para la investigación, la metodología utilizada fue la investigación descriptiva y exploratoria con características cualitativas de investigación. En una primera etapa de revisión de la literatura se llevó a cabo en los libros y artículos de revistas especializadas. En la segunda etapa fue realizada la investigación del campo que se llevó a cabo con el fin de recopilar datos sobre las comunidades utilizando técnicas de observación sistemática, entrevistas y cuestionarios semi-estructurados. Se ha observado como resultado que las comunidades y sus fiestas tradicionales tienen características que permiten la implementación de circuitos turísticos que rodean la Carretera Boiadeira. Sin embargo, para que el mismo sea estructurado con éxito todavía faltan reajustes necesarios en cada comunidad. Se cree que el desarrollo de la hoja de ruta ayudará a mantener vivas las tradiciones culturales de cada localidad.

Palabras clave: Ruta turística; Carretera Boiadeira; Turismo rural.

\section{Introdução}

Com o avanço da modernização no campo, dentre outros aspectos, as grandes propriedades se expandiram sobre os pequenos sitiantes que foram vendendo os seus bens e se deslocaram para a cidade (SILVA, 1998). A despeito desse cenário, muitos agricultores de base familiar 
ainda resistem no campo, como apontaram os dados do Instituto Brasileiro de Geografia e Estatística em seu último senso agropecuário (IBGE, 2009). Essa realidade não é diferente no entorno da Estrada Boiadeira (BR - 487), região localizada no interior do Estado do Paraná. Isso porque, na localidade, esses agricultores ainda mantém vivas as tradições de seus antepassados organizando e celebrando festas juninas; festas gastronômicas; festas religiosas e demais atividades culturais que reforçam as representações sobre seu o modo de vida.

Com os atributos naturais existentes nos arredores da estrada (cachoeiras, matas nativas, fundos de vale, riachos); o artesanato local (crochê, tapetes, colchas); as pequenas agroindústrias (produção de queijos, linguiças, pastéis, paçocas, requeijão, galinhas caipiras congeladas) e a gastronomia típica (costela no chão, costela no espeto, coxinhas com massa de mandioca, pastel caseiro, bolos caseiros, frangos assados inteiros, escondidinho de mandioca, brigadeiro de mandioca e outros) a região torna-se atrativa para uma demanda de habitantes citadinos interessados nessas características.

Muitos moradores urbanos viajam para o campo com o intuito de reencontrar suas raízes, interagir com a comunidade local, participar de suas festas tradicionais, desfrutar da hospitalidade e aconchego nas propriedades, conhecer o patrimônio histórico e natural no meio rural, conviver com os modos de vida, tradições, costumes e com as formas de produção das populações do interior. A realização da atividade turística no campo, portanto, veio para agregar valor ao modo de vida de muitas famílias que ainda continuam nestas localidades.

Observou-se, nesse sentido, nas festas tradicionais das comunidades localizadas na Estrada Boiadeira, atributos que indicaram potencial para a implantação de roteiro turístico, que de muitas maneiras pode auxiliar no fortalecimento dos grupos sociais nela localizados. Assim, o problema de pesquisa apresentado nesse trabalho foi: as festas tradicionais nas comunidades rurais da Estrada Boiadeira possuem atributos potenciais para o desenvolvimento de um roteiro de Turismo Rural?

Com o intuito de solucionar a problemática abordada foram levantadas duas hipóteses. A primeira delas foi de que existe interesse das comunidades; demanda potencial; atrativos importantes; recursos financeiros de infraestrutura e de gestão que viabilizam a implementação do roteiro. Já a segunda hipótese referiu-se a ineficiência de articulação entre as comunidades impedindo o desenvolvimento do roteiro. 
Com base no contexto apresentado o objetivo geral da pesquisa foi investigar os atributos para implantação de roteiro turístico no entorno da BR - 487, conhecida popularmente como Estrada Boiadeira. Buscou-se com os objetivos específicos identificar as festas existentes na região; levantar dados pertinentes junto aos representantes das comunidades sobre as festas; avaliar o interesse das comunidades e do público participante sobre a estruturação do roteiro turístico; observar a infraestrutura e serviços de apoio existentes e aqueles necessários para a implantação do roteiro e apontar sugestões para a concretização da estruturação do mesmo.

O estudo se baseou em pesquisa descritiva e exploratória, tendo como característica a pesquisa qualitativa. Em um primeiro momento foi realizada revisão da literatura em livros, artigos científicos e demais matérias da internet sobre os temas abordados. Em um segundo momento foi realizada a pesquisa de campo, com o intuito de levantar dados sobre as comunidades pesquisadas, utilizando os métodos de observação sistemática, entrevistas semiestruturadas e questionários. Em um terceiro momento foi utilizado para a análise de implantação do roteiro turístico, as orientações apontadas pelo Ministério do Turismo, encontradas na cartilha "Turismo Rural: Orientações básicas" (BRASIL, 2010), onde se encontram as bases para o desenvolvimento do segmento. A partir dessas orientações foi realizada avaliação sobre a possibilidade em implantar o roteiro na localidade observando-se os potenciais e os pontos que devem ser adequados.

Justificou-se o desenvolvimento deste trabalho pela possibilidade em despertar o interesse das próprias comunidades e dos visitantes da região em conhecer, com mais detalhes, a história do surgimento das festas tradicionais de cunho religioso que acontecem nessa localidade. Esse fator valoriza e revaloriza as tradições, que com o passar dos tempos, estão se perdendo em meio à intensa urbanização do campo. Há também uma diversificação na economia das famílias agricultoras, pois as mesmas gostam de receber visitantes e venderem os seus produtos, o que pode ser proporcionado com maior eficiência com a implantação de um roteiro.

Observou-se, também, que os estudos e publicações acerca da Estrada Boiadeira e das famílias que residem em seu entorno são escassos. Nesse sentido o estudo aprofundado nestas comunidades rurais visou despertar o interesse de estudiosos e pesquisadores sobre as temáticas abordadas como: o histórico da Estrada Boiadeira; as discussões sobre o turismo nos espaços rurais; a agricultura de base familiar e o desenvolvimento no ambiente rural. Para além, buscou-se sensibilizar os moradores vizinhos e todas as comunidades sobre a relevância 
das festas tradicionais de cunho religioso além de levantar a importância desse potencial turístico pelo seu valor histórico, social, turístico e cultural.

O trabalho foi dividido em seis partes. A primeira delas refere-se a presente introdução. A segunda trata dos procedimentos metodológicos adotados na pesquisa. A terceira parte denominada "O 'novo rural' brasileiro e os roteiros de turismo rural", debateu temas relacionados às mudanças sofridas no campo e sobre o turismo rural como nova atividade na realidade desse espaço.

A quarta parte nominada "A Estrada Boiadeira e suas comunidades: um olhar para o roteiro de Turismo rural" faz uma discussão sobre as características de cada comunidade, desde seu histórico, população, atrativos e trata de cada festa típica que ocorre em cada uma delas.

A quinta parte do trabalho intitulada "O roteiro e as festas tradicionais no entorno da Estrada Boiadeira: algumas reflexões" procura desenvolver as análises, realizadas com base na cartilha do Ministério do Turismo "Turismo rural: orientações básicas" e nos demais instrumentos empregados nessa pesquisa, sobre a implementação do roteiro de Turismo Rural nessas comunidades. E, por fim, na última parte do trabalho encontram-se as considerações finais sobre a pesquisa.

\section{Procedimentos Metodológicos}

O universo proposto para o desenvolvimento dessa pesquisa envolve cinco comunidades de agricultores de base familiar em um trecho de $40 \mathrm{~km}$ no interior do Estado do Paraná na BR 487, popularmente conhecida como Estrada Boiadeira. A estrada possui uma extensão total de 659,50 km, dividindo-se em 115,70km no Estado do Mato Grosso do Sul e 543,80 km no

Estado do Paraná. É uma importante ligação entre as regiões produtoras do Centro Oeste brasileiro e da região Noroeste do Estado do Paraná com o Porto de Paranaguá.

O trecho em que as comunidades estudadas se encontram está na transição do asfaltamento da Estrada Boiadeira, onde a estrada de acesso de um distrito se encontra sem asfalto (DNIT, 2014). No trecho estudado é possível encontrar mercados, mercearias, postos de gasolina, postos de saúde, borracharias, restaurantes, além dos grandes e pequenos lavradores. A agricultura da região se baseia no plantio de mandioca, milho, soja, trigo e cana de açúcar 
(IBGE, 2009). Esse percurso de $40 \mathrm{~km}$ envolve quatro municípios no interior do Paraná: Cianorte, Tuneiras do Oeste, Araruna e Campo Mourão.

As comunidades estudadas (FIGURA 01) foram a Comunidade $\mathrm{km} 128$ (pertencente ao município de Campo Mourão), a Comunidade Colônia UPÁ (pertencente ao município de Araruna), a Comunidade Alto Beijamim Costant e o Distrito São Lourenço (pertencentes ao município de Cianorte) e, por fim, o distrito Guaraitava (pertencente ao município de Tuneiras do Oeste). Essas comunidades foram selecionadas como objeto desse estudo em razão do número de manifestações, por meio de festas tradicionais, de seu patrimônio imaterial que se coloca como fator potencial para o Turismo Rural, somadas aos demais atrativos e a organização das comunidades que extrapolam as fronteiras dos municípios onde se localizam evidenciando a relevância da base comunitária.

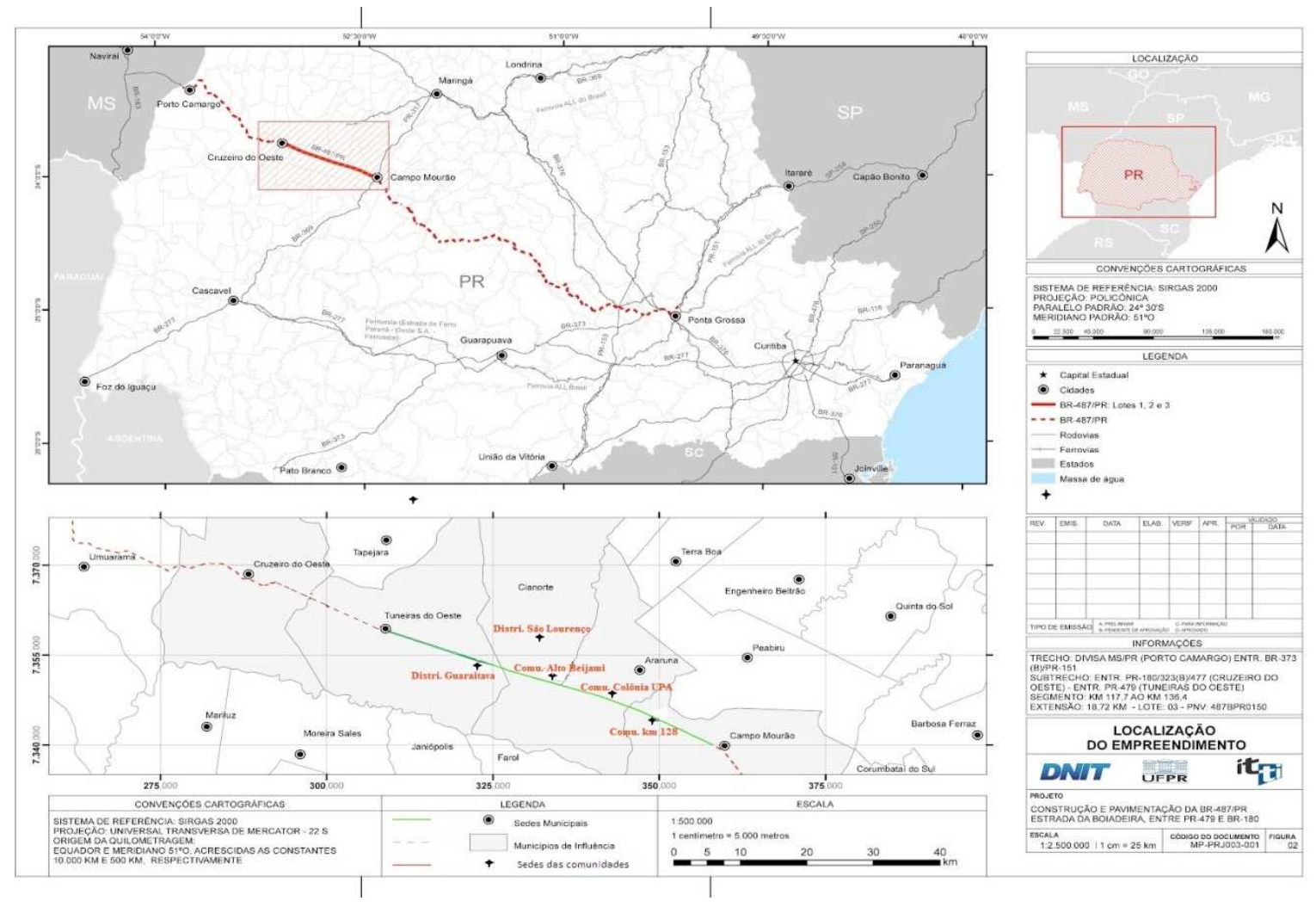

Figura 01: Localização das comunidades da Estrada Boiadeira.

Fonte: DNIT, 2014. Organizado pelas autoras

Para comprovar as hipóteses casuais do referente trabalho, o estudo se baseou na pesquisa descritiva e exploratória. A pesquisa descritiva tem como objetivo avaliar diversos aspectos, dimensões ou componentes a serem pesquisados, juntamente com a pesquisa exploratória que 
tem como objetivo principal descobrir novas ideias e novas perspectivas (SCHLÜTER, 2003). O caráter qualitativo da pesquisa se preocupa em analisar e interpretar as características mais profundas, descrevendo e fazendo análises sobre as descobertas da investigação (LAKATOS e MARCONI, 2007).

Para o melhor desenvolvimento da pesquisa, em um primeiro momento foi realizada uma revisão da literatura sobre o tema abordado com levantamento em livros, artigos científicos e demais materiais na internet. Os temas estudados foram às características dos municípios em questão (que são propostas como atrativos para o turismo); o turismo rural e os roteiros de turismo rural; sobre a resistência das festas tradicionais de comunidades rurais; sobre a gastronomia típica do campo, dentre outros, o qual o poder público pretende fortalecer por meio da atividade turística; e sobre os aspectos do próprio turismo que ocorre no campo. A finalidade da revisão é colocar o pesquisador em contato direto com tudo o que foi escrito, dito ou filmado sobre o determinado assunto (MARCONI e LAKATOS, 2007).

Em um segundo momento utilizou-se à pesquisa de campo. A metodologia de trabalho empregada na pesquisa de campo se baseou na observação sistemática, uma vez que há a necessidade de traçar parâmetros de análise para manter objetividade nos estudos realizados (MARCONI e LAKATOS, 2007). Esse tipo de observação foi utilizado com o intuito de levantar dados sobre as comunidades, identificando assim a estrutura utilizada para acomodar os participantes nas festas tradicionais, os atributos existentes nas festas e nas comunidades e o envolvimento delas na realização dos eventos.

Foram aplicadas também entrevistas semiestruturadas para a coleta das informações. As entrevistas foram aplicadas apenas com os organizadores das festas que foram selecionados em razão da função que ocupam totalizando cinco entrevistas. A finalidade dessas entrevistas foi de levantar informações como à viabilidade da divulgação das festividades existentes na área; quais são as dificuldades encontradas na realização do evento; se a falta de recurso impede ou dificulta a realização festividade; entre outros. A coleta desses dados ocorreu no período de fevereiro a setembro de 2014.

Por fim, as orientações do Ministério do Turismo, também foram aplicadas. Tratou-se da cartilha "Turismo Rural: Orientações básicas", segunda edição. No material se encontram as bases para o desenvolvimento do segmento. A partir da cartilha foi realizada avaliação sobre a 
possibilidade em implantar o roteiro na localidade, observando-se os potenciais e os pontos que devem ser adequados para a concretização do mesmo.

Foram levados em consideração seis fatores para analisar a viabilidade de implantação do turismo rural nas localidades. O primeiro fator é a identificação e análise de recursos; o segundo é o estabelecimento de parcerias e formação de redes; o terceiro é o envolvimento da comunidade local; o quarto é a agregação de atratividade e diversificação; o quinto é o incentivo ao desenvolvimento e o sexto é a acessibilidade.

\section{O "Novo Rural" Brasileiro e os Roteiros de Turismo Rural}

Diversos autores defendem a urbanização do campo como característica marcante no cenário da realidade brasileira. Tal defesa baseia-se em decorrência de mudanças significativas como o aumento da ocupação não agrícola, o avanço da pluriatividade, a modernização das atividades agropecuárias, a chegada da infraestrutura, o avanço das agroindústrias, o desenvolvimento dos meios de comunicações e do "[...] transbordamento do mundo urbano naquele espaço que tradicionalmente era definido como rural." (SILVA, 1998, p.43).

Esse processo está alterando profundamente não só as formas de organização do processo de trabalho, mas também diminuindo a escala mínima necessária da atividade econômica e redefinindo os requisitos fundamentais de sua localização espacial. Com todas essas mudanças, as políticas rurais direcionam-se basicamente para reduzir o isolamento das populações rurais melhorando as suas condições de vida e de qualificação (SILVA, 1998).

Observa-se esse cenário, pois, em muitos países as comunidades rurais não possuem um impacto significativo no Produto Interno Bruto (PIB), porém, em contrapartida elas concentram significativos volumes de recursos que atualmente estão escassos em outros setores da economia (TRUKHACHEV, 2015).

Com o período pós-industrial, e dentro desse contexto da melhoria de vida no campo, os agricultores começaram a combinar atividades agropecuárias com outras atividades não agrícolas, dentro ou fora de suas propriedades, variando os ramos da atividade, sendo elas tradicionais ou novas como o turismo, o lazer, a gastronomia e a conservação da natureza 


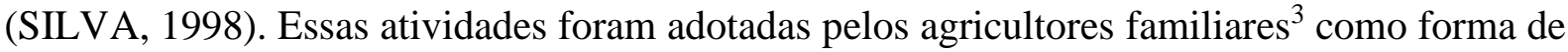
alternativa de renda para manter-se no campo.

Essas famílias de agricultores começaram a trabalhar em suas pequenas propriedades com atividades não agrícolas, que antes eram compreendidas como de fundo de quintal ou hobbies e, que passaram a ser geradoras de renda como pesqueiros, floriculturas, criação de pequenos animais, fabricação de doces, apicultura, suinocultura, criação de aves (galinha, avestruz e ema) entre outras atividades (SILVA, 2002). Essas características típicas do meio rural, envolvendo a paisagem natural, o patrimônio cultural e os modos de vida das populações rurais, passam a atrair um número cada vez maior de pessoas do meio urbano, fortalecendo assim a prática do TR.

Este quadro em que a família começa a se dedicar a essas atividades pode ser explicado de várias formas, mas o que se destaca entre todos são dois motivos. $\mathrm{O}$ primeiro trata do aumento do tempo livre que muitos agricultores passaram a ter. Atualmente existem máquinas que plantam, colhem e até ordenham animais, fazendo com que esses trabalhadores realizassem as suas atividades que antes demandavam muito tempo em um menor período. $\mathrm{O}$ segundo motivo refere-se ao fato que com as dificuldades vividas no campo diminuem as oportunidades em se trabalhar diretamente na agropecuária. Muitas famílias, nesses casos, começam a liberar outros membros da família para buscar formas, na cidade, de aumentar a renda com outros trabalhos remunerados (SILVA, 1998).

Com essas transformações, surge o que vem sendo chamado de "Novo Rural" brasileiro, onde o campo passa a ser utilizado para novas ocupações de trabalhos e modo de vida, deixando de ser exclusivamente agrícola. As famílias que passaram, nesse contexto, a combinar as atividades agrícolas com as aquelas não agrícolas (SILVA, 1998). Como atividades não agrícolas Schneider (2009) considera os ramos ou setores da economia como a indústria, o comércio, os serviços e turismo.

Como atividade não-agrícola o Turismo Rural (TR) não é uma atividade turística nova, sua primeira manifestação foi no século XIX, na Europa, com o objetivo de amenizar o estresse causado pela urbanização e expansão das cidades industriais. Surgiu em contraposição ao

\footnotetext{
${ }^{3}$ Entende-se por agricultura familiar segundo a Lei 11.326, de 24 de julho de 2006 como aquela que possui mão-de-obra extremamente familiar dentro da propriedade; em que a gestão do estabelecimento cabe à própria família; em que a área da propriedade não supera quatro módulos fiscais e a principal fonte de renda da família se origina de atividades econômicas vinculadas ao estabelecimento (BRASIL, 2006).
} 
turismo de massa que antes era intimamente relacionado ao turismo de sol e praia (ARAUJO, 2010).

Vários fatores contribuíram para o desenvolvimento do TR, desde o seu surgimento, um desses fatores, de maior relevância, foi à modernização da agricultura. Isso ocorreu porque com o advento do êxodo rural e da busca por alternativas para o campo houve uma preocupação do setor público na manutenção dos pequenos agricultores nas áreas rurais, pois devido à grande urbanização dos centros industriais; stress da vida da cidade houve uma valorização do meio rural, da cultura e do ambiente que deixou de ser visto como espaço atrasado e passou a ser utilizado para o descanso, lazer e contato com o meio ambiente. O TR foi visto, portanto, como uma atividade aceleradora do desenvolvimento rural, onde está relacionado com a facilidade de criar empregos, pois envolvem uma série de atividades que podem ser geradoras de renda para as comunidades que vivem no meio rural, como industrialização de alimentos, artesanato, trilhas e passeios ecológicos (WANDSCHEER e TEIXEIRA, 2010).

Em sua forma mais original o TR em sua estrutura apresentava traços rurais e de pequena escala, ao ar livre e proporcionava ao turista um grande contato com a natureza, com a herança cultural das comunidades do campo (RUSCHMANN, 2000). Com o objetivo de promover a sociabilidade, a integração entre o rural e o urbano junto com a transformação socioeconômica, contribuindo para amenizar a pobreza no campo, sem realizar o processo de aculturação surge o TR que deve ter como objetivo aumentar a renda dos agricultores, gerar empregos, diminuir o êxodo rural, desenvolvendo assim o local e a região turística. (TULIK, 2003).

No Brasil o TR foi implantado em 1986 em Lages, SC, onde as propriedades rurais foram abertas as visitações com o intuito de promover um dia de campo com pernoite e participação nas lidas ${ }^{4}$ do campo. A partir deste momento a atividade começou a ser caracterizada como TR e entendida como oportunidade de aumentar a renda das famílias (RODRIGUES, 2003).

No final de 1990 o TR foi espalhado pelo país, fazendo com que aumentassem os empreendimentos em todas as regiões interessadas pelo segmento. Alguns desses empreendimentos estavam preparados ou buscavam melhorar seus produtos e a prestação de

\footnotetext{
${ }^{4}$ Entende-se por lidas do campo as atividades realizadas no interior de fazendas, ranchos, sítios, chácaras entre outros, como por exemplo, tratar das criações, colherem os ovos, realizar o plantio.
} 
serviços, porém, em contrapartida, muitas outras experiências não tinham corpo técnico qualificado para a execução das atividades e sim apenas a vontade de trabalhar com TR (ZIMMERMANN, 2000). Diante dessa realidade surgiram alguns pontos negativos para a implantação da atividade. De modo geral cita-se a sobrecarga da estrutura rural; elevados números de visitantes e veículos; problemas legais; degradação ambiental e descaracterização do meio e da atividade turística (ZIMMERMANN, 2000).

O turismo no espaço rural, em razão das suas ambiguidades e experiências diversificadas, por vezes acaba, em sua definição, englobando várias modalidades de turismo como o ecoturismo, o turismo verde, o turismo cultural, esportivo, de aventura, eventos, entre outros. Além disso, como existe uma relação de interdependência entre turismo no espaço rural e turismo rural, se torna necessário esclarecer o que se entende por essas terminologias (ARAUJO, 2010).

Nesse sentido o Ministério do Turismo ao tratar das orientações básicas para o segmento considera o turismo no espaço rural ou em áreas rurais como:

Todas as atividades praticadas no meio não urbano, que consiste de atividades de lazer no meio rural em várias modalidades definidas com base na oferta: turismo rural, turismo ecológico ou ecoturismo, turismo de aventura, turismo de negócios e eventos, turismo de saúde, turismo cultural, turismo esportivo, atividades estas que se complementam ou não (BRASIL, 2010a, p.17).

Pode-se entender o turismo no espaço rural, portanto, como qualquer atividade de lazer e turismo que seja realizada em áreas rurais, evolvendo além do agroturismo, outras atividades como hospedagem, alimentação, operação e agenciamento, transportes de visitantes, realização de eventos entre outros (ARAÚJO, 2010).

Enquanto o TER se refere a todos os movimentos turísticos ocorridos no espaço rural o TR se restringe às características próprias do meio rural, à paisagem, ao estilo de vida e à cultura rural, excluindo-se formas não ligadas à prática e ao conteúdo rural (TULIK, 2003).

Existem várias definições para o TR, dentre elas, mais uma vez, destaca-se a definição do organismo responsável pela atividade no país, compreendendo o segmento como:

[...] um conjunto de atividades turísticas desenvolvidas no meio rural, comprometido com a produção agropecuária, agregando valor a produtos e serviços, resgatando e promovendo o patrimônio cultural e natural da comunidade (BRASIL, 2010a p. 18). 
Com o desenvolvimento do TR, portando, deve-se buscar o fortalecimento da produção agropecuária, em que, com a implantação e realização das atividades turísticas agrega-se valor ao modo de vida e produção no campo, não deixando de tratar o segmento como uma alternativa e compreendendo que "The rural tourism is a complex concept that includes both the service provider and the consumer, and local community interests and expectations." (STREIMIKIENE; BILAN, 2015, p. 31).

Uma das muitas maneiras de desenvolver o segmento de Turismo Rural é a organização de roteiros turísticos em meio rural. Isso porque, dentre outras questões, os roteiros de turismo podem promover parcerias e somar atrativos e produtos turísticos próximos que de muitas maneiras pode ser benéfico para turistas e para a localidade.

Considera-se um roteiro turístico o " [...] itinerário caracterizado por um ou mais elementos que lhe conferem identidade, definindo e estruturando para fins de planejamento, gestão, promoção e comercialização turística" (BRASIL, 2007, p.28). O roteiro turístico é marcado por sua flexibilidade, não exigindo sequência de visitação e uma de suas características é a tematização do roteiro que vai imprimir uma identidade única para cada roteiro elaborado, podendo, a rota ${ }^{5}$ ou o roteiro turístico passar por uma ou mais regiões turísticas ${ }^{6}$ (BRASIL, 2010b).

Sabe-se que as políticas públicas de turismo voltadas para o processo de roteirização, independente da tipologia da atividade turística, têm como principal função a redução da pobreza e a inclusão social. De acordo com a proposta do MTur pode- se dizer que a roteirização de ser participativa estimulando a integração e compromisso de todos, promovendo a inclusão social, preservando a cultura e o ambiente (BRASIL, 2004).

Os roteiros podem aumentar as taxas de visitação, permanência e gasto médio dos turistas, resultando, nesse sentido, em uma geração e ampliação do mercado de trabalho a longo e médio prazo, na inclusão social, na estabilidade econômica, dentre outros benefícios (BRASIL, 2010a).

${ }^{5}$ Diferente do roteiro na rota turística existe uma sequência na ordem dos destinos a serem visitados e há sempre um ponto inicial e um ponto final (BRASIL, 2007).

${ }^{6}$ Compreende-se como região turística um "[...] espaço geográfico que apresenta características e potencialidades similares e complementares, capazes de serem articuladas e que definem um território" (BRASIL, 2010b, p.31). 


\section{As Festas Tradicionais das Comunidades da Estrada Boiadeira}

A Estrada Boiadeira foi criada com o intuito de transportar gado de Mato Grosso até o Paraná para o abastecimento da capital paranaense. Durante sua construção houve desenvolvimento regional para municípios paranaenses como Pitanga, Campo Mourão, Cruzeiro do Oeste e Icaraíma. Através da Estrada Boiadeira, chegavam também os especuladores de terras, que por muitas vezes agiam de forma violenta para empossar as propriedades. A estrada foi responsável pelo progresso regional de Guarapuava, Pitanga e Campo Mourão. De Campo Mourão a estrada continuou avançando até a barranca do rio Paraná que faz divisa com Mato Grosso do Sul (ESTRADA BOIADEIRA, 1995).

Atualmente existem várias comunidades no entorno da Estrada Boiadeira que se mantêm no campo mesmo mediante as dificuldades encontradas. Uma das formas de auxílio para a manutenção dessas comunidades, para o fortalecimento de suas riquezas culturais e naturais é a atividade do turismo. Exemplo disso são as festividades das comunidades que trazem grandes quantidades de turistas para participar de seus costumes e deixam nessas localidades uma renda extra, conforme narrou o Padre da Paróquia de São Lourenço ${ }^{7}$ do Distrito de São Lourenço. Dentre elas, estão a Comunidade Km 128; Colônia UPÁ; Comunidade Alto Beijamim Constant; Distrito de São Lourenço e Distrito do Guaraitava.

Assim como as pesquisas de Silva $(1998 ; 2002)$ apontaram a realidade do campo brasileiro que sofre com o êxodo rural e é marcado pela busca de alternativas para a manutenção das populações rurais no campo foram observadas nas comunidades estudadas tal realidade. Em

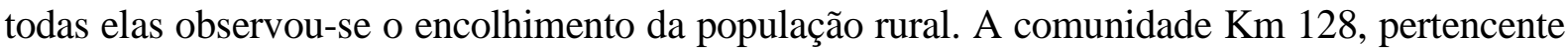
ao município de Campo Mourão, por exemplo, possui famílias que trabalham em seus pequenos sítios para a sua subsistência, sendo necessário para melhorar a renda, em alguns casos, complementar com o trabalho na cidade. Ainda, a comunidade no auge da agricultura do café e algodão possuía aproximadamente 50 famílias e as mesmas trabalhavam para os serialistas de Campo Mourão. Atualmente ela conta com 20 famílias morando no seu entorno, tendo como infraestrutura principal uma escola municipal, uma igreja, uma biblioteca e um bar.

Para ajudar nas despesas da comunidade a igreja promove festejo religioso que acontece no mês de Julho de cada ano. A festa tradicional conta com gastronomia local com pratos salgados feitos no fogão a lenha e pratos doces. Além da gastronomia oferta-se o bingo que

\footnotetext{
${ }^{7}$ Em entrevista coletada mês de setembro de 2014 (Duração 1 h).
} 
conta como premiação as doações da própria comunidade. Em dia de festa a comunidade recebe aproximadamente seiscentos visitantes ${ }^{8}$.

A infraestrutura para receber o público, conta com uma Capela, dois banheiros sendo um feminino e outro masculino e com um campo de futebol onde ocorrem atividades diversas com crianças e jovens. Como não há barracão comunitário fixo, nos dias de festa são colocadas, na cozinha da escola municipal, barracas provisórias de lona para acomodar os visitantes. As refeições são feitas pelas mulheres da comunidade e os produtos utilizados são doados pela comunidade $\mathrm{Km} 128$ e pelas comunidades vizinhas. Os únicos itens comprados para a festa são as bebidas. Contrata-se apenas serviço de som. O organizador da festa relata que não há muita divulgação, pois infraestrutura não comporta maior número de pessoas.

Além do festejo a comunidade conta ainda com vários atrativos naturais ou artificiais e culturais. A maioria desses potenciais turísticos se encontra às margens da Estrada Boiadeira, sendo de fácil acesso. Dentre eles existe o "Haras das Estrelas", local para hospedagem e lazer; produtores familiares de hortas orgânicas; pista para trilhas de motocross; pesque e pague; recanto de lazer com campo de futebol; rios e cachoeiras propícios para banho e pesca e ainda um antigo cemitério que é motivo de visitação e curiosidade para o público externo a comunidade. Sobre a demanda esses atributos evidenciam os fatores chave que motivam:

[...] the desire to escape from routine, the desire for pleasure and recreation, the search for unforgettable lifetime experience, the search for adventures, the pursuit of intellectual enrichment, the desire to learn more about the nature, the desire for security, the search for beautiful landscaping, the search for quiet, low noise and environmental pollution, and the search for availability (STREIMIKIENE; BILAN, 2015, p. 31).

A comunidade Colônia UPÁ pertence ao município de Araruna e se localiza às margens da Estrada Boiadeira. A maioria das famílias que vivem no entorno da comunidade e trabalham com lavouras (mandioca, milho, soja, trigo); nas indústrias locais de beneficiamento de farinha de mandioca; com a criação de pintainhos para aviários locais e algumas famílias da comunidade trabalham no município de Araruna para aumentar a sua renda. A comunidade foi colonizada por ucranianos que ainda mantém as suas tradições como a missa que ainda é rezada em latim com o sacerdote de costas para os fiéis. O santo de devoção da igreja Ucrâniana é São João e no dia de São João ocorre à festa na Comunidade.

${ }^{8}$ Em entrevista coletada mês de agosto de 2014 (Duração 1h 25 min.). 
A infraestrutura da festa conta com a Igreja, um barracão comunitário capaz de suportar quatrocentos e cinquenta pessoas sentadas, uma cozinha grande onde se preparam as refeições, dois banheiros (um feminino e outro masculino), um campo de futebol onde ocorre o torneio de futebol suíço, ou o torneio de truco que se intercalam pelas edições da festa.

O cardápio da festa é tradicional da comunidade com frango assado em pedaços, frango assado inteiro, costela assada e acompanhamentos. As cozinheiras são as mulheres da comunidade e voluntárias que desejam ajudar, os homens ficam responsáveis pelo dinheiro, bebidas e carnes. Os produtos utilizados na festa são $60 \%$ da comunidade e comunidades vizinhas, o restante é arrecadado por meio de doações em produtos ou em dinheiro. Durante a festa promove-se baile que é muito famoso na região. A animação do baile fica por conta dos sanfoneiros da comunidade. Nos dois dias de realização da festa comparecem aproximadamente dois mil e quinhentos visitantes ${ }^{9}$.

A comunidade tem atrativos turísticos naturais (rios e áreas de mata preservada) e culturais. Destaca-se a própria missa em latim com ritos específicos dessa tradição e a arquitetura da Igreja Ucraniana São João. Além disso é possível encontrara agroindústria familiar com pequenas farinheiras, produção de queijos e doces de origem vegetal e o plantio e beneficiamento de café (onde ainda se encontram os famosos 'terreiros de secar café'). Observando esses atributos da comunidade entende-se que:

[...] one of the most valuable competitive advantages of rural areas over urban ones is that they harmoniously combine natural and cultural values into a unique mixture of attractions. The increasing trend of last decades in the developed countries (and of last years in the developing part of the world) is rural tourism. Tourism is an effective tool to attract investments and promote interest in rural ways of life, traditions and local identities of rural areas. As an alternative source of income in addition to the traditional agricultural production, rural recreation is especially important in developing countries and economies in transition [...] (TRUKHACHEV, 2015, p. 3053).

Essa realidade não é diferente na Comunidade Alto Beijamim Constant que pertence ao município de Cianorte e está localizada cerca de $1 \mathrm{~km}$ da Estrada Boiadeira e a $27 \mathrm{~km}$ de Campo Mourão. As famílias que ainda residem nesta comunidade moram nos sítios, porém trabalham nas farinheiras das proximidades. Cerca de 30 anos atrás a comunidade contava com 70 famílias, devido à falta de condições das estradas e geadas que ocorreram na época

${ }^{9}$ Em entrevista coletada mês de agosto de 2014 (Duração 1h e 19 min.). 
muitas famílias venderam seus sítios para os grandes fazendeiros que ainda moram na localidade. Atualmente a comunidade do Alto Beijamim Constant conta com 17 famílias que ainda se mantém na comunidade. Isso ocorre porque parte da comunidade deseja sair, mas não possui outro local para viver e outra parte da comunidade gosta de morar onde nasceu ${ }^{10}$. A comunidade conta, em seu ponto central, com a Igreja São João Batista (que não sofreu grandes alterações deste a sua construção), três casas ao seu redor e um bar.

A comunidade conta com a Capela, um barracão comunitário com cozinha que comporta duzentas pessoas sentadas. Para melhor acomodar os visitantes os organizadores colocam mesas coletivas no lado de fora do barracão em meios as árvores, dois banheiros (sendo um feminino e outro masculino), um campo de futebol onde ocorre o torneio de futebol suíço.

O cardápio tradicional da festa conta com costela assada em fogo de chão e acompanhamentos. Cerca de $65 \%$ dos produtos utilizados para fazer essas refeições são da comunidade Alto Beijamim e comunidades vizinhas, o restante é comprado. A comunidade contrata o serviço de som festa e os festejos se realizam no mês de Junho. Em dia de festa a comunidade recebe cerca de duas mil pessoas e um dos grandes problemas é a quantidade de carros que se acumulam na área central da comunidade (FIGURA 03).

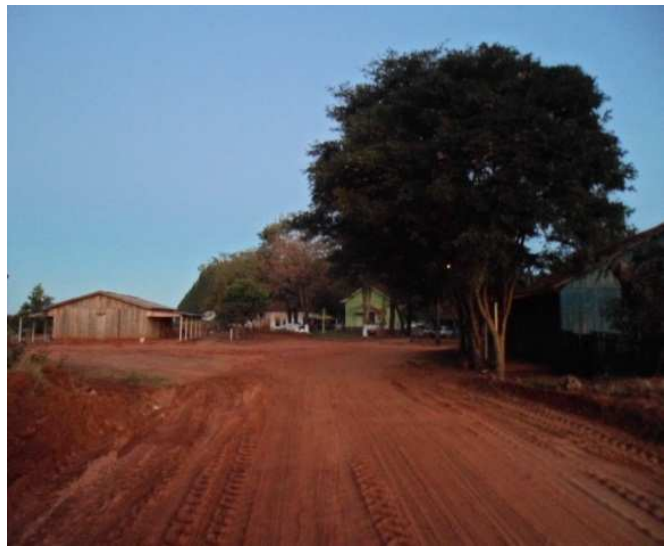

Figura 02: Comunidade em dias normais

Fonte: Acervo particular das autoras

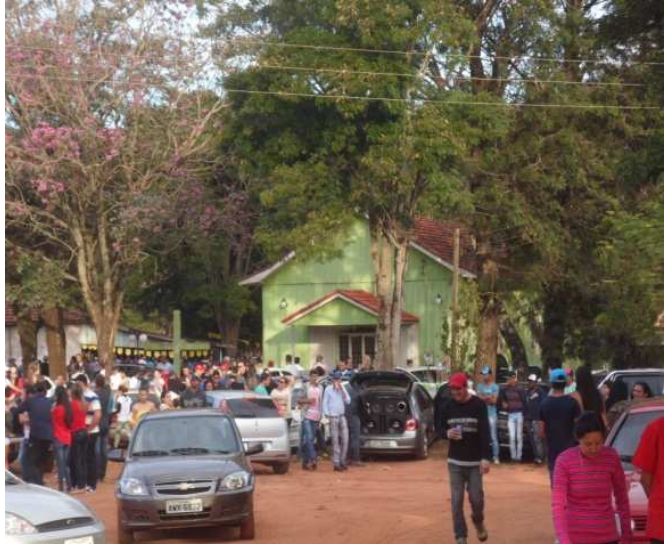

Figura 03: Comunidade em dias de festa

Fonte: Acervo particular das autoras.

Cruz (2008) assevera que é necessária uma infraestrutura mínima para receber turistas com uma estrutura específica para a atividade, superando as expectativas de uma demanda ávida pelas características do cenário bucólico do mundo rural.

${ }^{10}$ Em entrevista coletada mês de agosto de 2014 (Duração 2h). 
Além do festejo a comunidade conta com outros atrativos como cachoeiras (cachoeira do 40, cachoeira do Bambu e Cachoeira do Zé); rios propícios para banho e pescas (rio Tamboré e rio Ligeiro); hortas hidropônicas; horta em estufa e uma pequena Agroindústria Dos Passos onde se faz paçocas, pastéis e doce de leite.

O Distrito de São Lourenço pertence ao município de Cianorte e está cerca de $17 \mathrm{~km}$ de distância da Estrada Boiadeira. A sua população cerca de 20 anos atrás era de 1700 habitantes que residiam no distrito e trabalhavam no campo. Atualmente essa realidade é diferente, pois a maioria dos sitiantes vendeu suas propriedades e se mudaram para a cidade ${ }^{11}$.

A Festa Tradicional da Mandioca, que ocorre no distrito é a festa de maior proporção do roteiro que se realiza no mês de Agosto em comemoração ao Santo do distrito, São Lourenço. A infraestrutura da festa conta com a Paróquia São Lourenço, um barracão comunitário capaz de acomodar cerca de seiscentas pessoas sentadas, uma cozinha industrial, churrasqueiras, dois banheiros (um feminino com quatro sanitários e outro banheiro masculino com quatros sanitários).

O cardápio tradicional da festa é a base de mandioca contando com escondidinho de mandioca com frango, escondidinho de mandioca com carne, brigadeiro de mandioca, mandioca cozida, mandioca frita, maionese de mandioca. Porém outros pratos podem ser encontrados para quem não aprecia a iguaria. Os produtos utilizados no preparo das refeições são $80 \%$ do distrito os outros $20 \%$ a Igreja compra. O que mais chama atenção nesta festividade são os produtos derivados da mandioca e o bingo. Participam da festividade cerca de duas mil pessoas.

$\mathrm{Na}$ realização da festividade além de se encontrar a gastronomia tradicional é possível conhecer os pequenos agricultores de base familiar da região que vendem seus produtos na festa como artesanato local (colchas bordadas, panos de pratos pintados, panos de pratos bordados e flores de estufa).

A agricultura do distrito é baseada na produção de mandioca, milho e soja. Existem pequenos produtores rurais que trabalham de forma cooperada na Associação de Agricultores Familiares de São Lourenço (AFSAL) onde se tem cultivo de morangos; hortas orgânicas tradicionais com hortaliças em geral; hortas hidropônicas; cultivos de maçãs e peras; criação

\footnotetext{
${ }^{11}$ Em entrevista coletada mês de agosto de 2014 (Duração1h e 15min.).
} 
de galinhas caipiras e artesanato. A AFSAL conta com 12 famílias associadas que trabalham com produtos naturais. O objetivo principal da associação é incentivar e proporcionar a produção e oferta ao consumidor de produtos orgânicos com pouco ou nenhum defensivo agrícola. Sobre essa questão Woortmann (2004), demonstra que o camponês possui um modo específico de organizar sua propriedade. E essa organização obedece aos desejos da terra. É importante ressaltar que esse saber não é obtuso e atrasado, mas, sim, cauteloso. O cuidado com a lavoura e com o trato da natureza significa, também, preocupação com a família. A autora entende que o camponês não pode pôr em risco a reprodução social de sua família com a utilização de uma inovação tecnológica.

No distrito se encontram atrativos naturais como os rios propícios para banho e pesca (rio porto de areia, cachoeira do pezão, rio ligeiro) trilhas de Motocross e orquidários. Atrativos culturais também podem ser encontrados como as representações folclóricas em festas juninas que todos os anos são apresentadas a população por meio de promoções escolares e o artesanato em entalhe de madeira que expressa as características da comunidade.

O distrito do Guaraitava pertence ao município de Tuneiras do Oeste. Localiza-se à margem da Estrada Boiadeira. Sua economia é baseada no cultivo de mandioca, soja, milho e cana de açúcar. O distrito conta com 80 famílias segundo o último senso realizado (IBGE, 2009).

A infraestrutura da festa conta a Capela, um campo de futebol onde ocorre o famoso torneio de futebol suíço do Guaraitava, um barracão capaz de suportar cinquenta pessoas sentadas e uma cozinha pequena. Para melhor acomodar os visitantes são feitas improvisadas de lona e bambu e, em dias de festa o distrito chega receber duas mil pessoas.

O cardápio da festa conta com costela assada na brasa e acompanhamentos. Os produtos utilizados na cozinha são $50 \%$ da comunidade e comunidades vizinhas e os outros $50 \%$ são comprados pela igreja. O que mais chama atenção nesta festa é o seu famoso baile com a eleição da Miss Simpatia Guaraitava, onde só moradoras do distrito podem participar independentemente da idade além do grandioso torneio de futebol suíço.

No final de semana da festa o distrito chega a receber cerca de dois mil visitantes. Para atender a demanda a Emater juntamente com o SENAR oferta às mulheres do distrito cursos de capacitação em panificação (FIGURA 04). 


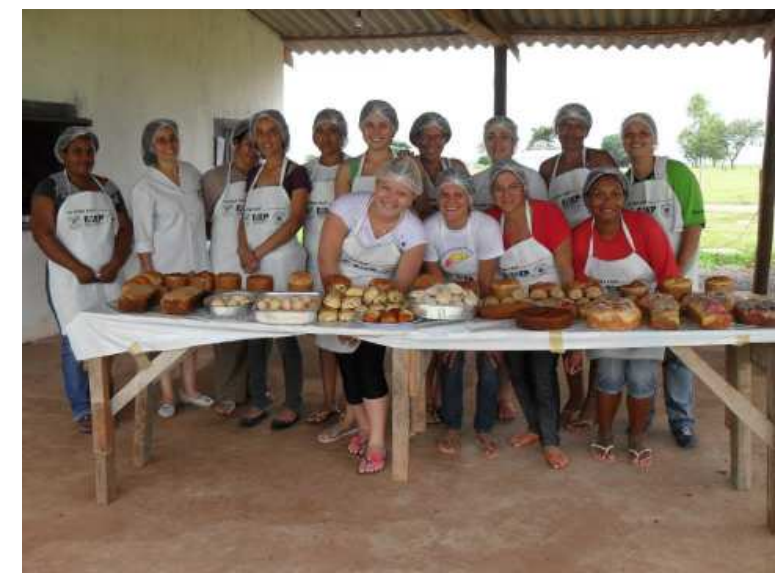

Figura 04: Panificação dos bolos e pães

Fonte: Carvalho, Maria. 2012. (Arquivo pessoal)

Esse curso de capacitação acontece de forma esporádica, de acordo com as necessidades da população do distrito. As participantes da capacitação são mulheres que residem no distrito e na região. Sobre essa questão é importante compreender que:

In order to create rural tourism development model, one should first determine which factors motivate the local community to develop rural tourism. These reasons are different in different areas. In some areas tourism development motives are related to the economic problems, which solution is the necessity to find new business niches; while in other areas, the main reasons for the development of rural tourism is based on the favorable opportunities of tourism development. The motives and considerations play an important role in the rural tourism development as well (STREIMIKIENE; BILAN, 2015, p. 31).

Buscar a capacitação para atender novos nichos de mercado pode ser uma saída por meio do turismo rural para valorizar o trabalho da mulher, a tradição da gastronomia local. Porém entende-se também que um modelo de desenvolvimento deve ser estudado e pensado para a localidade. Ações isoladas podem não surtir o efeito esperado.

Além dos atrativos da festa, o distrito conta com diversos atrativos naturais como as matas que atuam como corredores ecológicos da região (Mata do Canta Galo, Mato da Companhia, Mato da estradinha) e, dentro desses corredores se encontram várias lagoas naturais de água doce (lagoa dos patos, lagoa da Companhia, lagoa de Tuneiras entre outras). Ao lado do distrito se encontram a Reserva Biológica das Perobas. 


\section{Possibilidades de Roteirização das Festas Tradicionais no Entorno da Estrada Boiadeira: algumas reflexões}

Na cartilha do Ministério do Turismo “Turismo Rural: Orientações básicas”, segunda edição, são levados em consideração seis fatores para analisar a viabilidade de implantação do Turismo rural nas localidades. O primeiro fator é a identificação e análise de recursos; o segundo é o estabelecimento de parcerias e formação de redes; o terceiro é o envolvimento da comunidade local; o quarto é a agregação de atratividade e diversificação; o quinto fator é o incentivo ao desenvolvimento e o sexto e último fator é a acessibilidade (BRASIL, 2010).

Analisando o primeiro fator sobre a identificação e análise de recursos a metodologia aponta que para verificar a viabilidade de uma localidade desenvolver o Turismo rural é preciso realizar um inventário dos recursos naturais, materiais e imateriais que seja capaz de motivar o turista até a região (BRASIL, 2010).

Diante deste critério foram levantados e descritos os recursos das comunidades em questão como os humanos, naturais, culturais e de infraestrutura e, observou-se que as mesmas já possuem recursos estruturados e a serem estruturados que movimentam os turistas para a localidade. As festas das comunidades trazem pessoas de todas as regiões (Cianorte, Campo Mourão, Araruna, Tuneiras do Oeste, Umuarama, Farol, Peabiru, Engenheiro Beltrão, Tapejara, Doutor Camargo, Curitiba e etc.). Porém muitas questões devem ser trabalhadas como exemplo a infraestrutura ainda precária de algumas festividades. Além disso, observa-se a necessidade de realização de inventariação das comunidades e suas festas. Nesse sentido deve-se dar atenção as teorias dos modelos de desenvolvimento de turismo rural onde observa-se que a disponibilidade de recursos de atrativos naturais, refúgios e recursos naturais, recursos humanos, infraestrutura e outros são indispensáveis para o crescimento positivo do segmento (STREIMIKIENE; BILAN, 2015).

Analisando o segundo fator que é o estabelecimento de parcerias e formação de redes observase que a "Parceria e cooperação são itens indispensáveis para o processo de desenvolvimento de um empreendimento, de uma comunidade ou de uma cadeia mais ampla e complexa." (BRASIL, 2010, p. 40). Observou-se na sua grande maioria a existência de cooperação e parcerias apenas entre as comunidades locais. Sugere-se, portanto, a realização de parcerias com universidades, escolas municipais e estaduais, hotéis, restaurantes e transportes. As escolas podem frequentar as comunidades como prática de ensino agregando valor às comunidades. As 
universidades dariam o suporte técnico na estruturação do roteiro e realização de pesquisas. Com o setor de hospedagem, alimentos e bebidas e transportes da região pode-se firmar parceria para melhor aproveitamento do movimento de turistas na região.

Compreende-se o terceiro fator, que é o envolvimento da comunidade local, como uma das partes mais importantes para o desenvolvimento da atividade turística. O segmento do Turismo Rural deve oportunizar a toda a comunidade a descoberta, a apreciação e a valorização de seu patrimônio de maneiras diferenciadas e inovadoras (BRASIL, 2010). Observou-se na realização da pesquisa que as comunidades e distritos possuem conhecimento sobre a história de sua localidade, sobre seu patrimônio, possuem orgulho de seus antepassados por todas as conquistas. Observou-se também que as comunidades interagem entre si ajudando uma a outra na organização das festas e são elas as protagonistas desse processo. Essa observação vai de encontro com a proposta de turismo rural como asseverou Tulik (2003).

O quarto fator de análise é a agregação de atratividade e, nesse item, observa-se que "O Turismo Rural é uma das atividades que mais sofre com os efeitos da sazonalidade, ou seja, com a instabilidade da oferta e da demanda em certos períodos do ano, principalmente com a alta e a baixa estação." (BRASIL, 2010, p. 46). Observa-se que no decorrer do ano, em dias em que não há festejo, para driblar a baixa sazonalidade podem ser desenvolvidas atividades no interior das propriedades dos agricultores valorizando seu modo de vida e produção.

O quinto fator trata do incentivo ao desenvolvimento do segmento. Conforme o Ministério do Turismo "O processo de desenvolvimento nas sociedades modernas está vinculado a disponibilidade e acessibilidade ao crédito, para expansão das atividades de produção de cada setor econômico." (BRASIL, 2010, p. 52). Para melhorar a infraestrutura das festas e dos demais atrativos, os agricultores podem buscar linhas de créditos que se adéquem as suas necessidades e forma de pagamento. Os agricultores familiares podem contar com a linha de crédito dos bancos oficiais ou podem obter crédito pelo Programa Nacional de Fortalecimento da Agricultura Familiar (PRONAF), que financia projetos individuais ou coletivos que gerem renda aos agricultores. Os interessados pelo desenvolvimento da atividade turística podem buscar auxílio do Sistema S, como o Sebrae, SENAR e algumas instituições de ensino técnico ou superior para dar suporte ao desenvolvimento do turismo. Porém é necessário compreender que tais acessos às políticas de desenvolvimento do turismo rural não são facilmente captadas pelos agricultores de base familiar como apontaram os estudos de Teixeira e Nagabe (2010). 
O sexto e último fator de avaliação trata da acessibilidade. Sabe-se que no processo de consolidação do produto turístico é preciso pensar na acessibilidade de todos os turistas, sem distinção (BRASIL, 2010). Diante deste fator observou-se que apenas uma festa possui as mínimas condições para receber o público com mobilidade reduzida, a Festa Tradicional da Mandioca. A festa possui entradas especiais e banheiros femininos e masculinos especializados para atender a esse público. Os demais atrativos não estão preparados para receber esse turista com necessidades especiais.

\section{Considerações Finais}

A pesquisa confirmou parcialmente a primeira hipótese levantada de que existe interesse das comunidades em desenvolver o roteiro de turismo rural com base nas festas tradicionais das comunidades da região estudada. A movimentação do público nos dias de festa evidenciou uma demanda potencial interessada não apenas nas festas mas também em conhecer os demais atrativos existentes. Porém, pode-se observar que os recursos financeiros, de infraestrutura e de gestão ainda são escassos e ineficientes para a implantação de um roteiro.

Para além, refutou-se a hipótese de que não há cooperação entre as comunidades do entorno da Estrada Boiadeira. Aponta-se, porém, que o possível impasse para a concretização do roteiro turístico se encontra nas governanças entre os municípios. Isso porque, esse trecho passa nos limites de quatro municipalidades diferentes que podem apresentar dificuldades em trabalhar de maneira integrada.

Nesse sentido, o objetivo de investigar os atributos para implantação de roteiro turístico no entorno da Estrada Boiadeira foi atingido. Observou-se que além dos atributos das próprias festas tradicionais com gastronomia local; músicas e danças locais; atividades diversas que caracterizam o modo de viver de cada comunidade estão agregadas a elas outros atributos.

Os atrativos naturais da região que podem agregar valor as atividades desenvolvidas pelos turistas que acabam permanecendo mais tempo nas comunidades. Existem, também, na região, locais para hospedagem e atividades de lazer que agregam valor as festividades e podem incentivar a permanência desses turistas. Além desses fatores, observou-se que os modos de produção das famílias locais como a produção de alimentos orgânicos, as hortas tradicionais e a forma como se constituí e organiza a propriedade são atributos importantes que denunciam potencial para o desenvolvimento de um roteiro de turismo rural. 
Dentre os fatores elencados para analisar a viabilidade de implantação da atividade (BRASIL, 2010) observou-se que os itens Parcerias e formação de redes; Incentivo ao desenvolvimento e Acessibilidade foram os pontos mais frágeis da região. A formação de parcerias e redes encontra dificuldades na organização das diferentes municipalidades para trabalhar com o turismo. O Incentivo ao Desenvolvimento se depara com os entraves de captação de recursos principalmente pelos agricultores de base familiar e por fim, a identificou-se que para o acesso tanto das informações sobre as festas tradicionais quanto para chegar até elas existem problemas com divulgação com as estradas e sinalização adequada para chegar a esses locais.

Por fim, observou-se que é necessário dar continuidade a pesquisa levantando com maior detalhamento as características de cada comunidade envolvendo estudos de planejamento, turismo de base comunitário, patrimônio cultural, dentre outros. Esses estudos sanariam as limitações da presente pesquisa que avaliou as cinco comunidades da região de maneira geral e que necessita observar com maior grau de verticalização cada comunidade. Para além, observa-se a necessidade em desenvolver maior número de pesquisa sobre festas tradicionais e as comunidades que promovem tais eventos com o objetivo de compreender a importância do turismo na valorização e revalorização dessas localidades bem como auxiliar em suas estruturações.

\section{Referências}

ARAUJO, J.G.F. Potencialidades do turismo no espaço rural: desenvolvimento, conceitos e tipologia. In: SANTOS E. O; SOUZA, M. (Orgs.). Teoria e prática do turismo no espaço rural. Barueri. São Paulo: Manole, 2010.

BRASIL, DEPARTAMENTO NACIONAL DE INFRAESTRUTURA DE TRANSPORTES (DNIT). Localização das comunidades da Boiadeira. 2014. Foto, color; 16x15. Disponível em $<$ http://www.dnit.gov.br/mapas-multimodais/mapas-multimodais/mapas-multimodais/mapasmultimodais/pr.pdf> Acesso em: mai.2014.

BRASIL, MINISÉRIO DO TURISMO. Introdução à regionalização do turismo. Brasília, 2007. Disponível em <http://www.ibam.org.br/media/arquivos/estudos/introducao_turismo.pdf > Acesso em: jul. 2014.

BRASIL, MINISTÉRIO DO TURISMO. Turismo rural: Orientações básicas. $2^{\mathrm{a}}$ edição, Brasília: Ministério do turismo, 2010.2 Disponível $\quad$ em <http://www.turismo.gov.br/export/sites/default/turismo/o_ministerio/publicacoes/downloads_publica coes/Turismo_Rural_Versxo_Final_IMPRESSxO_.pdf> Acesso em: ago. 2014.

BRASIL, M. T. Programa de regionalização do turismo - roteiros do Brasil: diretrizes políticas. Brasília: Ministério do turismo, 2004. 
BRASIL, SUPREMO TRIBUNAL FEDERAL. Decreto Lei $n^{o} 11.326$ de 24 de julho de 2006. Brasília, 2006. Disponível em <http://www.planalto.gov.br/ccivil_03/_ato20042006/2006/lei/l11326.htm> Acesso em: ago. 2014.

CRUZ, R. C. A. Turismo, produção do espaço e desenvolvimento desigual: para pensar a realidade brasileira. In: BARTHOLO, R; SANSOLO, D. G; BURSZTYN, I. (Orgs.). Turismo de base comunitária: diversidade de olhares e experiências brasileiras. São Paulo: Letra e Imagem, 2008.

ESTRADA BOIADEIRA. L W Editoração. Campo Mourão, Edição Semanal,1995, p.01-17.

INSTITUTO BRASILEIRO DE GEOGRAFIA E ESTATÍSTICA. Censo Agropecuário 2009. Disponível

<http://www.ibge.gov.br/home/estatistica/economia/agropecuia/censoagro/default.shtm>. Acesso em: maio 2014.

LAKATOS, E. M; MARCONI, M. A. Fundamentos de metodologia científica. 6. ed. São Paulo: Atlas, 2007.

RODRIGUES, A. B. Turismo Rural no Brasil - ensaio de uma tipologia. In: RODRIGUES, A. B. (Org.). Turismo rural: práticas e perspectivas. 2. ed. São Paulo: Contexto, 2003.

RUSCHMANN, D. O turismo rural e o desenvolvimento sustentável. In: ALMEIDA, J. A; FROELICH, J. M; RIEDL, M. (Orgs.). Turismo e desenvolvimento sustentável. Campinas, SP: Papirus, 2000. p. 63- 74.

SCHLÜTER, R. G. Metodologia da pesquisa em turismo e hotelaria. Tradução Tereza Jardini. São Paulo: Aleph, 2003.

SCHNEIDER, S. A pluriatividade no meio rural brasileiro: características e perspectivas para investigação. La pluriactividad em El campo latinoamericano, Equador, 2009.

SILVA, J. G. O novo rural brasileiro. 2. ed. Campinas, SP: UNICAMP, 2002.

SILVA, J. G. Novo rural brasileiro. Revista nova economia, 1998.

STREIMIKIENE, D; BILAN, Y. Review of Rural Tourism Development Theories. Transformations in Business \& Economics, Vol. 14, No 2 (35), p.21-34. 2015.

TULIK, O. Turismo rural. São Paulo: Aleph, 2003.

TRUKHACHEV, A. Methodology for Evaluating the Rural Tourism Potentials: A

Tool to Ensure Sustainable Development of Rural Settlements. Sustainability, Vol. 07, p. 3052-3050. 2015.

WANDSCHEER, E. A. R.; TEIXEIRA, A. R. Novas ruralidades: demanda e potencialidades da sociedade contemporânea. In: SANTOS E. O; SOUZA, M. (Orgs.). Teoria e prática do turismo no espaço rural. Barueri, São Paulo: Manole, 2010.

WOORTMANN, E. F. O saber tradicional camponês e inovações. In: OLIVEIRA, A. U.; MARQUES, M. I. M. (Orgs.). O campo no século XXI. Território de vida, de luta e de construção da justiça social. São Paulo: Casa Amarela/Paz e Terra, 2004.

ZIMMERMANN, A. Planejamento e organização do turismo rural no Brasil In: ALMEIDA, J. A; FROELICH, J. M; RIEDL, Mário (Orgs.). Turismo e desenvolvimento sustentável. Campinas, SP: Papirus, 2000, p. 127- 142.

\section{Recebido em: 02/07/2015 (1 ${ }^{\mathrm{a}}$ versão) 22/06/2016 ( $2^{\mathrm{a}}$ versão)}

Aprovado em: 20/07/2016 